\title{
Signal variability in replicate ice cores
}

\author{
Eric W. WOLFF, Eliza COOK, $*$ Piers R.F. BARNES, ${ }^{\dagger}$ Robert MULVANEY \\ British Antarctic Survey, Natural Environment Research Council, Madingley Road, Cambridge CB3 OET, UK \\ E-mail: ewwo@bas.ac.uk
}

\begin{abstract}
Replicate ice cores have been drilled about $\mathbf{1 0} \mathrm{m}$ apart for the top $\mathbf{7 9 0} \mathrm{m}$ of the ice sheet at Dome C, Antarctica. This provides an opportunity to examine inter-core variation of the signal for identical events, based on dielectric profile (DEP) comparisons. Comparison of the signal from the same core (a section $48 \mathrm{~m}$ long), measured 1 year apart, showed good reproducibility, with peak heights varying by around $10 \%$ between the two measurements. For the two replicate cores, identical peaks were matched and showed variability between cores of typically a factor $\mathbf{1 . 5}$. This can be explained based on the likelihood of significant time periods of missing accumulation in any single core at sites with such low snow accumulation rate. To synchronize core depths by matching peaks, it is essential to use the pattern of peaks, rather than just widely spaced individual strong peaks. To derive a quantitative volcanic index from these low-accumulation rate sites, it will be necessary to combine or average the results from several closely spaced parallel cores.
\end{abstract}

\section{INTRODUCTION}

Ice cores have been successfully used for defining trends in climate and related parameters over long time-scales (e.g. Petit and others, 1999; Johnsen and others, 2001). They have also been used over shorter time-scales, with particular success in showing trends in atmospheric pollutants (e.g. Candelone and others, 1995; Etheridge and others, 1996). Another strand of research has looked for the occurrence of individual, short-term events recorded in ice cores, of which the most notable example is large volcanic eruptions identified by the fallout of sulphuric acid (Hammer, 1977). After such eruptions, sulphate accumulates in the stratosphere, and deposits back into the troposphere and eventually to the ground over a period of 2-4 years. This is recorded in ice cores as strong enhancements of sulphate and of the electrical conductivity of solid ice (mainly representing acid), lasting for similar short periods. These volcanic sulphate or volcanic acid spikes are frequently catalogued for two main purposes: (1) they represent clear markers, often of known age, that can be used to assist in dating ice cores (e.g. Legrand and Delmas, 1987; Clausen and Hammer, 1988), or in matching two cores together (Wolff and others, 1999); (2) they can be used to generate records of past eruptive volcanic activity, of interest both to volcanologists and climatologists (Robock and Free, 1995).

In both such uses, it is critical to know how reliable the size and depth of each spike are. How much reliance should we place on the size of an individual peak, (a) when we identify and compare the same peak, or pattern of peaks, at different ice-core sites, and (b) when we compare the heights of different peaks (and therefore different eruptions) at the same site? For cores at widely different locations (especially when comparing Greenland and Antarctic cores), some differences can be expected due to inhomogeneity in the stratospheric sulphate layer and in the

*Present address: Royal Geographical Society, 1 Kensington Gore, London SW7 2AR, UK.

†Present address: CSIRO Telecommunications and Industrial Physics, PO Box 218, Lindfield, Sydney, New South Wales 2070, Australia. deposition from the stratosphere to the surface. Any attempt at a global volcanic index (e.g. the ice-core-volcano index (IVI; Robock and Free, 1995)) must therefore be a composite from different regions. For cores that are close together, and certainly for comparing individual peaks in a single core, local depositional noise is important (Fisher and others, 1985). We have the opportunity to study the variability introduced by such local variability along $790 \mathrm{~m}$ of two cores spaced approximately $10 \mathrm{~m}$ apart. Although our findings apply directly to the volcanic peaks, they will certainly also give information about the reliability of other chemical signals in ice cores.

\section{METHODS AND ICE-CORE SITE}

The study has been carried out on ice cores from the European Project for Ice Coring in Antarctica (EPICA) site at Dome C $\left(75^{\circ} 06^{\prime} \mathrm{S}, 123^{\circ} 21^{\prime} \mathrm{E}\right)$. The site is at $3233 \mathrm{~m}$ a.s.l., has a mean annual temperature of $-54.5^{\circ} \mathrm{C}$ and an annual accumulation rate of around $25 \mathrm{~kg} \mathrm{~m}^{-2} \mathrm{a}^{-1}$ (Stauffer and others, 2004). A first drilling at this site was halted when the drill became stuck at $788 \mathrm{~m}$ in 1999, but a new core at about $10 \mathrm{~m}$ distance from the old one exceeded this depth in the season 2000/01 (EPICA Dome C 2001-2002 science and drilling teams, 2002). At $788 \mathrm{~m}$, the age of the ice is estimated at $45 \mathrm{kyr}$ BP (Schwander and others, 2001). Among the measurements made on the core while it was still at Dome C was dielectric profiling (DEP) (Moore and others, 1989). This method measures the conductance and capacitance of the core at a range of frequencies. The method is applied to the uncut core before any other processing takes place. Lengths of $2.2 \mathrm{~m}$ were placed into a set of curved electrodes for measurement. The principal product at Dome $\mathrm{C}$ is the high-frequency conductivity at $2 \mathrm{~cm}$ intervals along the core. Although DEP does respond to other impurities in the ice (Wolff, 2000), under the conditions at Dome $C$ it responds almost entirely to the acidity of the ice (Wolff and others, 1999), so peaks in DEP conductivity are mainly volcanic. The temperature of the laboratory at Dome $\mathrm{C}$ was controlled to be in the range -17 to $-21^{\circ} \mathrm{C}$ (occasionally straying out of this range), and cores were left to equilibrate to this temperature. The temperatures were 


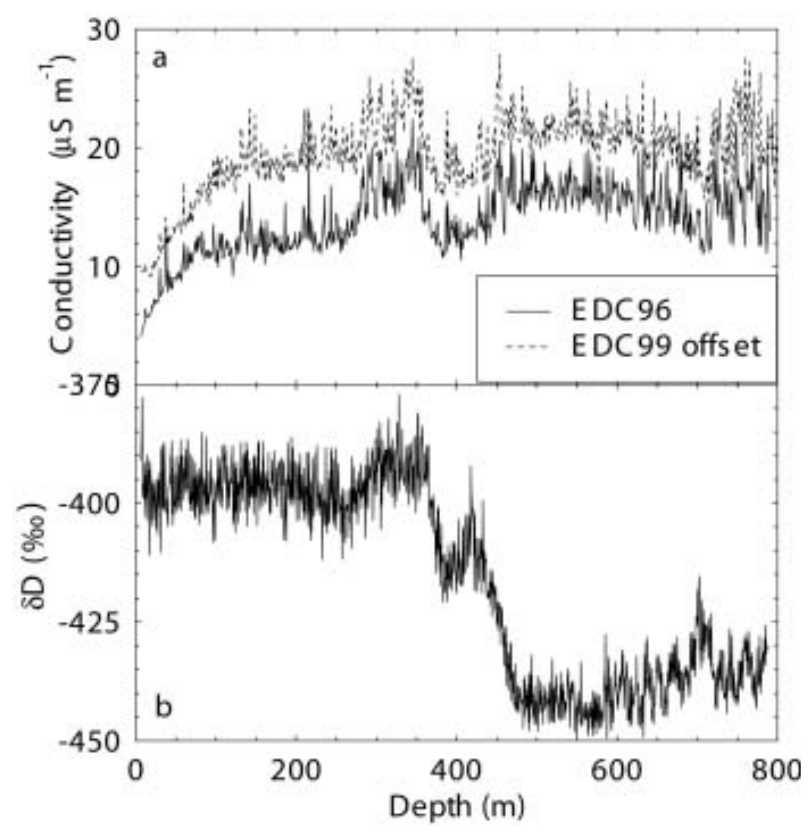

Fig. 1. (a) DEP $100 \mathrm{kHz}$ conductivities (temperature-corrected) of EDC96 and EDC99 (the latter offset by $+5 \mu \mathrm{S} \mathrm{m}^{-1}$ ). The data are smoothed to $1 \mathrm{~m}$ averages to show the general trends. (b) Deuterium from EDC96.

then used to calculate the conductivity at $-15^{\circ} \mathrm{C}$, using an empirical correction; full details are given elsewhere (Wolff and others, 1999).

The main part of this study refers to a comparison of two cores drilled near each other. The first core, EDC96, was processed soon after retrieval during the 1997/98 and 1998/ 99 seasons (except that the top $99 \mathrm{~m}$ were measured 2 years after drilling). The relevant section of the second core, EDC99, was processed soon after its retrieval in 2000/01.

In a separate comparison, a short section of deeper ice from EDC99 (between 1306.25 and 1354.65 m, representing a time-span of about 4600 years centred at $93 \mathrm{kyr}$ BP (EPICA community members, 2004)) was measured twice, once soon after retrieval in January 2001, and then again after the cores had been in a core buffer at Dome $C$ for 11 months, in December 2001; the aim was to determine how much of the inter-core variability was actually measurement uncertainty.

In all cases, the datasets consist of the conductivity measured at $100 \mathrm{kHz}$, corrected to $-15^{\circ} \mathrm{C}$, every $2 \mathrm{~cm}$ along the core. The general nature of the (smoothed) $788 \mathrm{~m}$ record can be seen in Figure 1, in which the deuterium profile is also shown (Jouzel and others, 2001); the Holocene period is in the top $360 \mathrm{~m}$ of core, and the transition into the last glacial period runs from 360 to $480 \mathrm{~m}$.

For the duplicate measurements of identical core (Fig. 2), there is no depth offset (at least within an uncertainty of perhaps $2 \mathrm{~mm}$, determined by the placement of the core in the electrodes). The two records can therefore be compared directly. Individual data points, as well as peaks with amplitude above various thresholds, were identified and compared. Individual volcanic spikes in the DEP record are superimposed on a background, due both to the continuous background acidity and to the high-frequency conductivity of pure ice (Wolff, 2000). We used both the absolute magnitude of conductivity, and the peak heights calculated after subtraction of a baseline. To estimate the baseline along

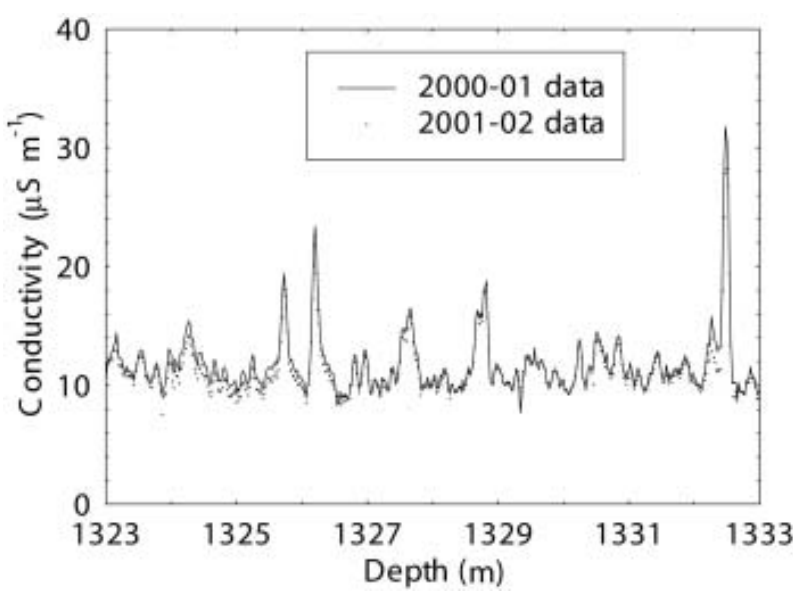

Fig. 2. A $10 \mathrm{~m}$ section of the duplicated measurements on EDC99. The data are DEP $100 \mathrm{kHz}$ conductivities (temperature-corrected).

the core, we calculated the lowest tenth percentile value of data $1 \mathrm{~m}$ above the peak depth, and the lowest tenth percentile value below the peak, and averaged the two values. Peak heights were calculated by subtracting the baseline value from the maximum peak conductivity.

For the comparison of cores EDC96 and EDC99, a number of reliable identical peaks were identified visually. The matching was carried out based on the pattern of peaks at a depth, as well as the height and shape of the peaks. The matching was carried out iteratively, with the largest, most obvious pattern matches made first to identify the local depth offset, and then intermediate peaks matched with relative depth constrained by the matches already made. Matches of large peaks were identified along the whole core, and a fuller analysis was carried out on two $50 \mathrm{~m}$ sections, one from the Holocene and one from the last glacial period. Both depth (to estimate offsets) and peak height (DEP conductivity) information were recorded for each match. For most of the analyses later in this paper, both the signal strength (i.e. the DEP conductivity value) and peak heights (after subtracting the baseline; see above) have been considered.

Statistics were carried out on the matched pairs of peaks from the two cores, to determine the uncertainty in individual peaks and to obtain an assessment of how it varies down the core and in different climatic periods.

\section{REPEATED MEASUREMENTS OF THE SAME CORE}

Figure 2 shows a section of the DEP profile for the repeated measurements on the core from around $1330 \mathrm{~m}$. The peaks tend to be rather wide (typically around $20 \mathrm{~cm}$, representing about 20 years at this depth) and in many cases quite symmetrical. This contrasts with modern findings that volcanic fallout should have a sharp onset, last for 2-3 years and have a tail (Rosen and others, 1994; Cole-Dai and Mosley-Thompson, 1999; Legrand and Wagenbach, 1999). It is clear that some kind of diffusional process has taken place (Barnes and others, 2003), broadening and flattening peaks. The same effect is seen, but less pronounced, in the shallower ice considered later. This diffusional process is another barrier to comparisons between volcanic records from places with very different glaciological characteristics, but should not have a large effect on the analysis we carry out here. 
Table 1. Statistics of signal strengths for the repeated DEP measurements of the ice-core section from 1306.25 to $1354.65 \mathrm{~m}$

\begin{tabular}{|c|c|c|c|c|}
\hline \multirow[t]{2}{*}{ Values used } & \multicolumn{2}{|c|}{ Conductivity } & \multicolumn{2}{|c|}{ Peak height ${ }^{*}$} \\
\hline & Mean ratio $^{\dagger}$ & SD of ratio & Mean ratio ${ }^{\dagger}$ & SD of ratio \\
\hline All values $(n=2420)$ & 0.97 & 0.05 & & \\
\hline Category $1(n=5)$ & 0.98 & 0.07 & 0.98 & 0.10 \\
\hline Category $2(n=39)$ & 0.95 & 0.04 & 0.92 & 0.10 \\
\hline Category $3(n=90)$ & 0.97 & 0.04 & 0.96 & 0.12 \\
\hline All peaks $(n=134)$ & 0.96 & 0.04 & 0.95 & 0.11 \\
\hline All peaks - geometric mean & 0.96 & $1.04^{\ddagger}$ & 0.94 & $1.13^{\ddagger}$ \\
\hline
\end{tabular}

*Peak height is the signal after subtracting a baseline value, as described in the text.

${ }^{\dagger}$ Ratio of later measurement to earlier measurement, i.e. $\mathrm{DEP}_{2} / \mathrm{DEP}_{1}$ (see text).

*Geometric standard deviation.

The close similarity between the datasets measured 11 months apart is apparent from Figure 2. When all the data points are plotted against each other and forced through the same zero intercept, they give an excellent linear regression $\left(r^{2}=0.96\right)$, and a best-fit relationship

$$
\mathrm{DEP}_{2}=0.964\left(\mathrm{DEP}_{1}\right) \text {, }
$$

where $\mathrm{DEP}_{2}$ is the later measurement, $\mathrm{DEP}_{1}$ is the earlier measurement and the values are in $\mu \mathrm{S} \mathrm{m}^{-1}$. This indicates that, as well as there being some measurement noise, the whole dataset is slightly reduced in value for the second measurement. This could be due to three possible reasons:

1. a change in the calibration of the LCR meter used to determine the dielectric parameters; the meter was not calibrated between seasons;

2. an error in the temperature correction coefficient (it turns out that the measurements were carried out at temperatures typically about $1.7^{\circ} \mathrm{C}$ different; an error of about $1 \%$ in the activation energy used would lead to a $1 \%$ bias in the calculated conductivity);

3. a change in the conductivity of the ice due to ageing during 11 months of storage.

We found that different $2.2 \mathrm{~m}$ sections behave as blocks with a different average ratio between the first and second measurements, suggesting that the temperature correction may indeed play a role. Because the measurement temperature was not stable at the $1^{\circ} \mathrm{C}$ level, it is difficult to unravel this further, but it emphasizes the need for precise temperature control if precise conductivities are required. Previous authors have suggested that an ageing effect in the months after drilling does significantly affect the conductivity measured by electrical conductivity measurement (ECM) (Schwander and others, 1983) or AC-ECM (Fujita and others, 2002). Our measurements allow a maximum of only a few per cent ageing effect, and it is likely that the effects seen by others are surface effects that do not contribute to the bulk DEP properties.

To assess the uncertainty in the height of a single peak from measurement to measurement (equivalent to the uncertainty between peaks due to measurement error), we look at the variability in the value of $\left(\mathrm{DEP}_{2} / \mathrm{DEP}_{1}\right)$. We have investigated the statistics for the entire dataset (2420 points) and also for peaks in different size ranges. We selected three ranges: (1) peaks above $30 \mu \mathrm{S} \mathrm{m}^{-1}$ (in either record); (2) peaks above $15 \mu \mathrm{S} \mathrm{m}^{-1}$; and (3) a more subjective selection of peaks that were significantly above background and clearly separated from neighbouring peaks. Within the $48.4 \mathrm{~m}$ section of ice, 5 peaks fell into category 1 (representing therefore 'once in a millennium' events), a further 39 peaks fell into category 2 (representing 'once in a century' events) and an additional 90 peaks fell into category 3, so that on average we have worked with 1 event roughly every 35 years. For the peaks, we have looked at statistics of the peak conductivity, but also for the peak height (i.e. after subtracting the baseline conductivity); the latter is more relevant for estimates of volcanic strength, and for comparison with other indices. Geometric means are also calculated, for comparison with data in Table 2.

The statistics are shown in Table 1. In summary, they suggest that individual DEP conductivities have an uncertainty of around $5 \%$, and that the uncertainty due to the measurement itself for a volcanic peak, for all categories of peak size, is around $10 \%$. This can arise partly from uncertainties in the instrument and the temperature, and also from small differences in the way the core is placed into the electrodes.

\section{LINING UP CORES EDC96 AND EDC99}

Having established the uncertainties that arise from repeat measurements of the same core, we now address the comparison of two different cores, located $10 \mathrm{~m}$ apart. The first issue in this case is to be able to compare peaks on a common depth scale. Logging procedures adhere to rigid guidelines to avoid discontinuities; ours were similar to those used elsewhere (Hvidberg and others, 2002). However, systematic and random errors are inevitable and accumulate with depth, and this culminates in depth offsets. It was relatively simple to line up identical peaks in the two cores, using both the size and shape of the largest and most definite matches first, and then interpolating between them using smaller peaks. Measured depth offsets, using the clearest matches (often but not always the largest peak) in each $10 \mathrm{~m}$ section, are shown in Figure 3.

The trend in offsets of EDC96 relative to EDC99 fluctuates between 0.10 and $0.30 \mathrm{~m}$ over the first $400 \mathrm{~m}$ (Fig. 3). The most likely explanation for these offsets is the accumulated errors accrued through the process of logging. Despite the stringent guidelines, small errors are likely to occur when fitting successive $\sim 3 \mathrm{~m}$ long cores together after drilling. Systematic errors (at the $\mathrm{mm} \mathrm{m}^{-1}$ level) can also accumulate if different loggers follow slightly different 




Fig. 3. Depth offsets down the two cores, estimated using the clearest matches (often, but not always, the largest peaks), with at least one in each $10 \mathrm{~m}$ section of core. A straight-line fit to the data above $80 \mathrm{~m}$, and a five-point smoothing below this depth, are shown.

procedures in marking and measurement. Part of the increase in the upper part is caused by a logging error that omitted the section 80.2-80.3 $\mathrm{m}$ in EDC96, thereby creating a $10 \mathrm{~cm}$ increase in offset at this depth (shown as a vertical line in Fig. 3). Between 500 and $800 \mathrm{~m}$, the offset increases significantly, probably due to difficulties in exact fitting of cores in this zone of brittle ice. The depth errors of around 1 part in 1000 are similar to those obtained in a similar exercise for the North Greenland Icecore Project (NorthGRIP) core (Hvidberg and others, 2002). Around the trend in offset, there is a scatter of order a few $\mathrm{cm}$, which must be due to roughness of the snow surface, and which will be treated in detail elsewhere. For other analyses in this paper, we considered two peaks to be potential matches if the depth of their maximum was within $6 \mathrm{~cm}$ of the mean offset at that depth.

Because we have already matched each peak and we use maximum conductivity values (which are actually averages across the $2 \mathrm{~cm}$ electrode width) for subsequent analyses, the maximum remaining depth offset between the two measurements is $1 \mathrm{~cm}$. This could induce differences between the two cores if peaks were narrow in comparison to $1 \mathrm{~cm}$; since most peaks are about $20 \mathrm{~cm}$ wide near their base and have wide, smooth tops, we estimate that the uncertainty introduced by this residual offset is of the order $5 \%$.

\section{COMPARISON OF PEAK HEIGHTS FOR EDC96 AND EDC99}

Comparisons of representative sections of the two cores are shown in Figure 4. Note that the relevant depth offset has already been applied by setting the data on different $x$ axes. This figure already illustrates many of the most important points of this paper: (1) over short sections, with a rather constant depth offset, clear patterns of matching peaks are easily identified; (2) many large peaks are similar in both cores; (3) however, it is possible for very significant peaks in one record to be rather ordinary peaks in the other record (e.g. $427.1 \mathrm{~m}$ in EDC99); moderate peaks in one record may be completely missing in the other core (e.g. $255.1 \mathrm{~m}$ and $693.8 \mathrm{~m}$ in EDC99).
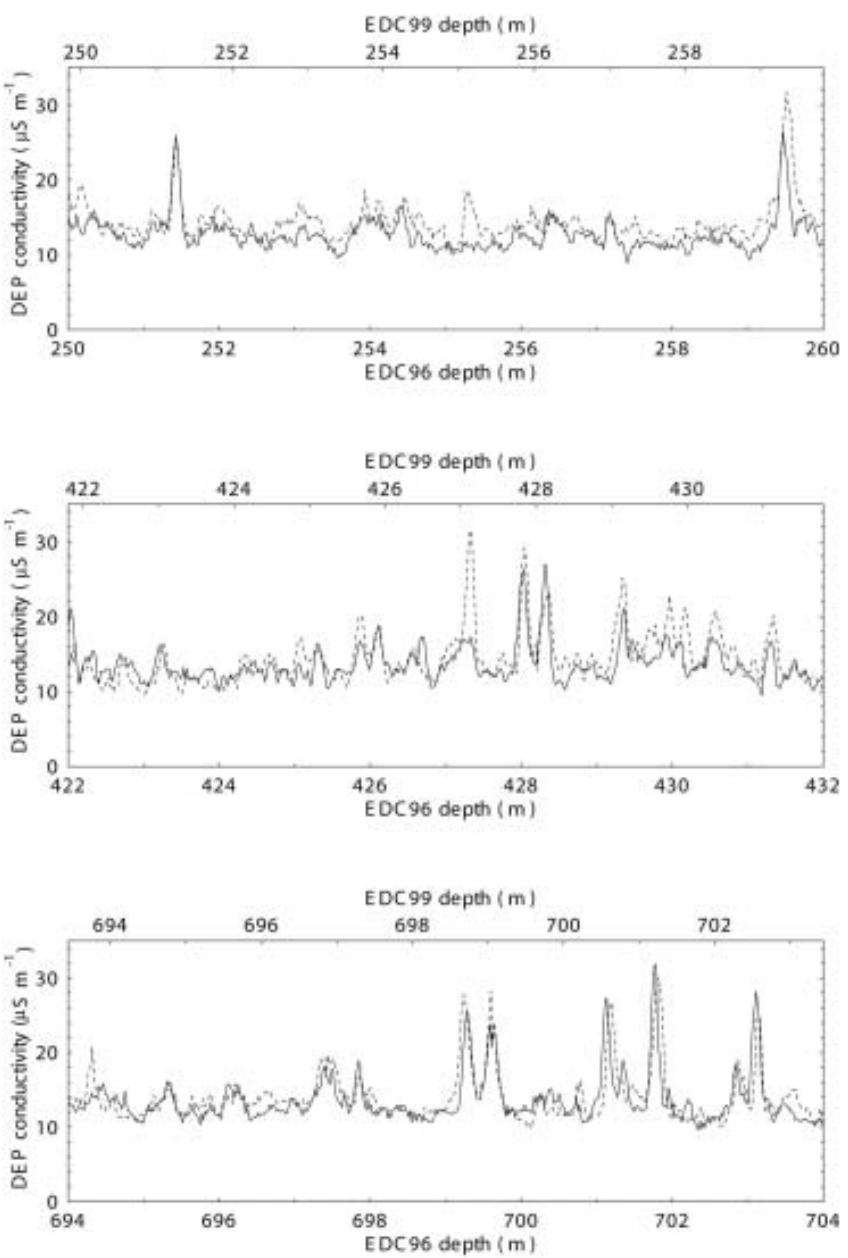

Fig. 4. Comparison of DEP $100 \mathrm{kHz}$ conductivities (temperaturecorrected) of EDC96 (solid curve) and EDC99 (dashed curve) in detailed $10 \mathrm{~m}$ sections of core from the Holocene, transition and last glacial period. EDC99 depth is offset (see top axis in each case) by 17,20 and $56 \mathrm{~cm}$ respectively.

To allow a comparison with the repeat data on identical cores (above), we first carried out a similar procedure, using two $50 \mathrm{~m}$ sections of core, one from the Holocene, one from the last glacial period. In each case, we used all signals where one of the peaks was more than $20 \mu \mathrm{S} \mathrm{m}^{-1}$. Although this is not the same conductivity threshold as used for the repeated measurements on a single core, it gives peaks on average 'once per century' in these records, similar to the frequency of category 2 peaks in Table 1 (250-300 m represents 1700 years in the Holocene in EDC1 chronology (Schwander and others, 2001) and has 19 peaks; 690-740 m represents 4000 years in the last glacial period in EDC1 chronology and has 30 peaks). The need for a changed threshold to produce a similar frequency of peaks is probably because, in the older ice of Table 1, peaks are somewhat smoothed, and not because of weaker eruptions. We carried out a similar analysis for the whole core, using the same peaks that were used for the initial alignment of the cores (see Fig. 3); these represent on average about 1 peak per 500 years.

Figure 5 a shows the peak heights for all these peaks in the two cores. Table 2 shows the statistics of these peaks, using the ratio of the conductivities and peak heights, as in Table 1. However, in this case there is a wide spread of values that we do not expect to be normally distributed (since values of the ratio can be greater or less than 1 ), so we 

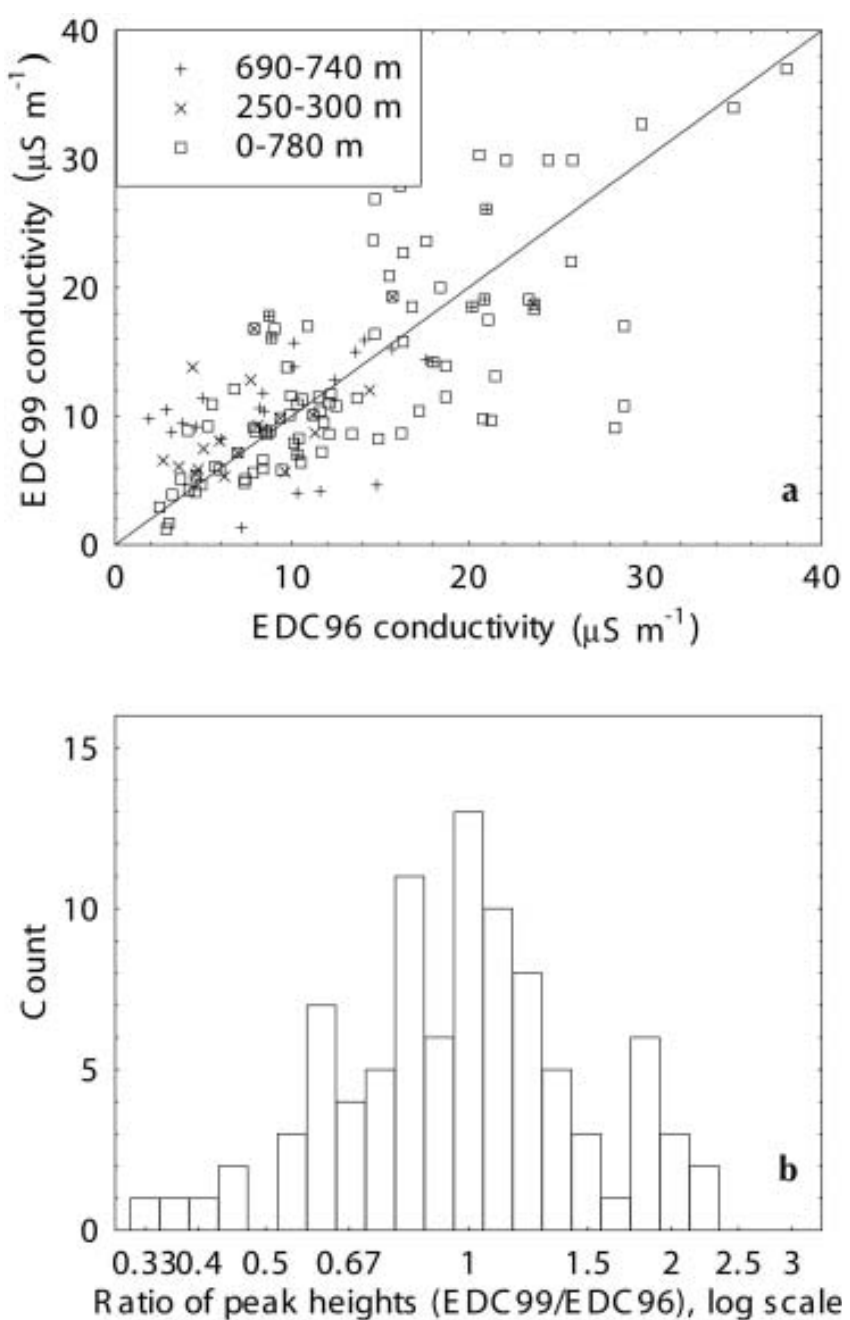

Fig. 5. (a) Plot of the measured peak heights in EDC96 and EDC99 for the peaks identified and used in Table 2; (b) histogram of the ratio of peak heights (after subtracting the background) for the 92 peaks in the bottom row of Table 2 .

have used geometric means and geometric standard deviations. The histogram in Figure $5 \mathrm{~b}$ confirms that the ratios have a distribution close to log-normal, although with slightly more values in the two tails than would be expected. Concentrating on the peak heights (as a measure of volcanic strength), we find that individual peaks have a geometric standard deviation (SD) of 1.5-2.0 (i.e. their height is uncertain by a factor 1.5-2). Note that, using the same calculation method, the repeated measurements (Table 1) gave an uncertainty of only factor 1.1 , and the residual depth offset induces only about a 5\% uncertainty, so we can be sure that most of the uncertainty here is due to spatial variability, and not to factors related to the measurement.

For the section from 250 to $300 \mathrm{~m}$, we carried out a full analysis, identifying all peaks, of whatever magnitude, by a procedure that searched for local maxima within $40 \mathrm{~cm}$ moving blocks. All these peaks can be seen in Figure 6 . The smaller peaks are of course very difficult to assign clearly to their counterparts in the other core. We carried out linear regression on the heights of matched peaks between the two cores. For peaks with amplitude $<5 \mu \mathrm{S} \mathrm{m}^{-1}$, peak heights are essentially uncorrelated, suggesting that peaks below this value are difficult to use for matching between cores, or for assessing the strength of volcanic eruptions.

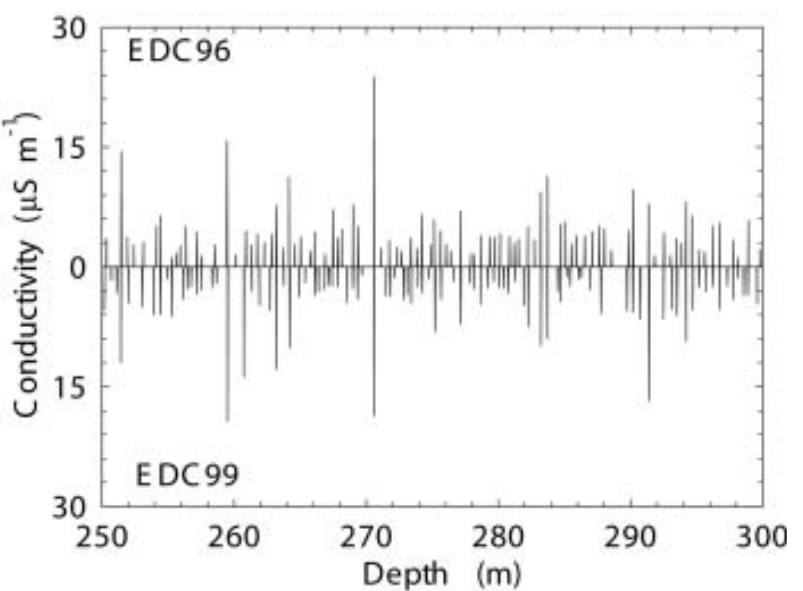

Fig. 6. Peak heights (after subtraction of baseline) for EDC96 and EDC99 between 250 and $300 \mathrm{~m}$ depth. All local maxima have been identified as discussed in the text.

\section{DISCUSSION \\ Causes of variability}

Our analysis shows that it is relatively easy to make a match between the volcanic peaks of closely spaced ice cores. However, for the Dome $C$ region, even for 'once in a century' eruptions, for any individual peak there is an uncertainty factor of at least 1.5 in the height recorded, and for peaks of smaller amplitude there is little information in the peak height (although the pattern of peaks may still be useful). Although we obtained larger uncertainties from the 690-740 $\mathrm{m}$ ice than from the shallower section, other analyses along the core do not suggest that the uncertainty becomes significantly greater with depth. Measurement uncertainty plays a very minor role, so the uncertainties we observe must be due to spatial variability of deposited acid.

Of course, the atmosphere is on average spatially homogeneous on $10 \mathrm{~m}$ scales over the periods of deposition after an eruption, so the variability can only be due to variability in snow deposition and erosion. Surface topography over small horizontal scales at Dome $\mathrm{C}$ is of order $5-8 \mathrm{~cm}$ (Palais and others, 1982) (equivalent to about 1 year's accumulation). It has been estimated that (under current conditions) about $10 \%$ of annual layers are completely missing at any single location (Petit and others, 1982). After large eruptions, stratospheric aerosol concentration decreases with an e-folding time of just under 1 year (Hofmann and others, 1987; Rosen and others, 1994); for an eruption of reasonable strength such as Pinatubo, Philippines, significant enhancement lasts for 3 years (Rosen and others, 1994) (and presumably longer for the largest eruptions).

In this paper, we follow common practice in using peak values rather than peak areas. If the complete first year of an eruption were missing, we could anticipate seeing an eruption with a factor $e$ lower peak than at a site where it is fully present. The way we have calculated our statistics suggests that peaks in adjacent cores are within a factor 1.5 of each other on $68 \%$ (1SD) of occasions. The 1 year e-folding time implies that the loss of 5 months' accumulation in one core at the peak would lead to a factor 1.5 lowering, similar to what we observed. Observations suggest that half the 
Table 2. Statistics of signal strength for identical peaks in sections of cores EDC96 and EDC99

\begin{tabular}{lccc}
\hline Core depth (EDC96 depth) & \multicolumn{2}{c}{ Conductivity } & Peak height \\
& Geometric mean ratio & Geometric SD & Geometric mean ratio \\
\hline $250-300 \mathrm{~m}(n=19)^{\dagger}$ & 1.09 & 1.18 & 1.23 \\
$690-740 \mathrm{~m}(n=30)^{\dagger}$ & 1.03 & 1.30 & 1.14 \\
$0-780 \mathrm{~m}(n=92)^{*}$ & 1.00 & 1.24 & 0.97 \\
\end{tabular}

*Peak height is the signal after subtracting a baseline value, as described in the text.

${ }^{\dagger}$ All peaks with conductivity $>20 \mu \mathrm{S} \mathrm{m}^{-1}$ in either core.

This analysis used the clearest large peak matches, with at least one match in every $10 \mathrm{~m}$ section.

year's accumulation is missing in $22 \%$ of cases (Petit and others, 1982). Our results are therefore consistent with what would be expected due to variable deposition and loss.

This analysis suggests that similar results should be found for any sites where the accumulation variability is of similar order to the accumulation rate. This is likely to be the case for most of the East Antarctic plateau (including Dome C, Vostok and Dome Fuji). However, we should expect better statistics at high-accumulation sites near the coast or in West Antarctica. One study of a single eruption (Pinatubo) at six closely spaced pits at South Pole (average snow accumulation rate $94 \mathrm{~kg} \mathrm{~m}^{-2} \mathrm{a}^{-1}$ ) (Cole-Dai and Mosley-Thompson, 1999) found an approximately $20 \%$ uncertainty in the volcanic flux for this eruption. When the same data are used to calculate the ratio for a single eruption between each pair of pits (analogous to our treatment), a factor 1.3 uncertainty is obtained. The lower uncertainty at South Pole than we obtained for Dome $\mathrm{C}$ reflects the higher snow accumulation rate at South Pole.

\section{Significance of signal strength for eruption peaks in single ice cores}

To compare volcanic eruption records between sites that are more widely spaced, it will be essential to use a pattern of peaks, firmly anchored by unequivocal matches, possibly in other parameters. In our analysis, we found that the largest peak in a given $10 \mathrm{~m}$ section was also the largest peak in the same $10 \mathrm{~m}$ section of the parallel core in only $45 \%$ of cases (this can already be seen in Figure 6: the largest peak in the two cores is the same for the 250-260 and $270-280 \mathrm{~m}$ sections, but not for 260-270, 280-290 or 290-300 m). Given that additional uncertainties must be introduced over larger spatial scales, comparisons of single, widely spaced large peaks could not be successful, and it is only when all information is included together, and the entire pattern of peaks considered, that a safe synchronization can be attempted (Wolff and others, 1999; Udisti and others, 2004). The problem will of course become much more acute when comparisons are made with distant regions where local volcanoes may also impact the record (such as in West Antarctica (Hammer and others, 1997)), or where interhemispheric comparisons are made.

This discussion also highlights the difficulties of obtaining representative ice-core volcanic indices from the cores currently available (Robock and Free, 1995; Cole-Dai and others, 2000). At least for the low-accumulation rate sites, the records so far obtained from single cores will simply not be representative, and no amount of averaging with records from other regions will make them so. If a reliable index is required, it is necessary to measure several parallel but closely spaced cores. From these, a representative regional signal should be obtainable (either by averaging the parallel signals or, if our explanation is correct, by taking the maximum value for each signal, on the basis that this is the one where the signal has not been lost). To reduce the factor 1.5 error on a single peak to a more acceptable factor 1.2 requires averaging of data from five parallel cores at a given site. With such a statistically improved record, we might expect that rather similar stratospheric signals would be recorded across Antarctica, with extra signals clearly identified as local tropospheric signals. Comparison with the Northern Hemisphere (Greenland; Langway and others, 1995) is then further complicated by the fact that many Greenland signals clearly derive from Iceland and are not expected to be significant in Antarctica.

\section{CONCLUSIONS}

This study has shown that volcanic signals (recorded by DEP) from a single core are reproducible within an uncertainty of about $10 \%$, but that from parallel cores there is a much larger uncertainty in any peak, of typically factor 1.5. This is easily explained by the loss of significant parts of a single year's accumulation at sites where surface topography and accumulation variability are comparable to the annual accumulation rate. It implies that, for comparison between cores, patterns of peaks with other strong stratigraphic ties are essential for accurate synchronization.

This study also indicates that ice-core volcanic indices from single cores at such low-accumulation sites cannot be reliable. What is required is a network of close-spaced records. While for long cores this requires an unrealistic amount of coring, new initiatives in which access holes can be drilled rapidly (Clow and Koci, 2002) make such an effort seem feasible, especially if the electrical measurements can be carried out rapidly in the field. New ideas for making electrical measurements in the borehole itself (complementing existing downhole optical methods (Bay and others, 2001; Hawley and others, 2003)) would also contribute; they might also sample a larger volume of ice so that the spatial inhomogeneity is smoothed out. Until such improved regional records are obtained, ice-core volcanic indices, especially those based on sites with low snow accumulation rates, must be treated as uncertain for individual eruptions by a large factor.

It would be desirable to carry out a study similar to this at sites with higher accumulation rates, so that uncertainties can be quantified at these sites too. Finally, this study indicates that sharp signals in other parameters must also be treated cautiously: for example, although seasonality may be 
present in sites with moderate accumulation rates, the heights of seasonal maxima should not be expected to exhibit comparable patterns between cores.

\section{ACKNOWLEDGEMENTS}

This work contributes to the European Project for Ice Coring in Antarctica (EPICA), a joint European Science Foundation/ European Commission (EC) scientific programme, funded by the EC and by national contributions from Belgium, Denmark, France, Germany, Italy, The Netherlands, Norway, Sweden, Switzerland and the UK. This is EPICA contribution No. 124

\section{REFERENCES}

Barnes, P.R.F., E.W. Wolff, H.M. Mader, R. Udisti, E. Castellano and R. Röthlisberger. 2003. Evolution of chemical peak shapes in the Dome C, Antarctica, ice core. J. Geophys. Res., 108(D3), 4126. (10.1029/2002JD002538.)

Bay, R., P. Price, G. Clow and A. Gow. 2001. Climate logging with a new rapid optical technique at Siple Dome. Geophys. Res. Lett., 28(24), 4635-4638.

Candelone, J.P., S. Hong, C. Pellone and C.F. Boutron. 1995. PostIndustrial Revolution changes in large-scale atmospheric pollution of the Northern Hemisphere by heavy metals as documented in central Greenland snow and ice. J. Geophys. Res., 100(D8), 16,605-16,616.

Clausen, H.B. and C.U. Hammer. 1988. The Laki and Tambora eruptions as revealed in Greenland ice cores from 11 locations. Ann. Glaciol., 10, 16-22.

Clow, G.D. and B. Koci. 2002. A fast mechanical-access drill for polar glaciology, paleoclimatology, geology, tectonics and biology. Nat. Inst. Polar Res. Mem., 56, 5-37.

Cole-Dai, J. and E. Mosley-Thompson. 1999. The Pinatubo eruption in South Pole snow and its potential value to ice-core paleovolcanic records. Ann. Glaciol., 29, 99-105.

Cole-Dai, J., E. Mosley-Thompson, S.P. Wight and L.G. Thompson. 2000. A 4100-year record of explosive volcanism from an East Antarctic ice core. J. Geophys. Res., 105(D19), 24,431-24,441.

EPICA community members. 2004. Eight glacial cycles from an Antarctic ice core. Nature, 429(6992), 623-628.

EPICA Dome C 2001-2002 science and drilling teams. 2002. Extending the ice core record beyond half a million years. EOS Trans. AGU, 83(45), 509-517.

Etheridge, D.M., L.P. Steele, R.L. Langenfelds, R.J. Francey, J.M. Barnola and V.I. Morgan. 1996. Natural and anthropogenic changes in atmospheric $\mathrm{CO}_{2}$ over the last 1000 years from air in Antarctic ice and firn. J. Geophys. Res., 101(D2), 4115-4128.

Fisher, D.A., N. Reeh and H.B. Clausen. 1985. Stratigraphic noise in the time series derived from ice cores. Ann. Glaciol., 7, 76-83.

Fujita, S. and 6 others. 2002. Electrical measurements on the 2503 m Dome F Antarctic ice core. Ann. Glaciol., 35, 313-320.

Hammer, C.U. 1977. Past volcanism revealed by Greenland ice sheet impurities. Nature, 270(5637), 482-486.

Hammer, C.U., H.B. Clausen and C.C. Langway, Jr. 1997. 50,000 years of recorded global volcanism. Clim. Change, 35(1), 1-15.

Hawley, R.L., E.D. Waddington, R.A. Alley and K.C. Taylor. 2003. Annual layers in polar firn detected by Borehole Optical Stratigraphy. Geophys. Res. Lett., 30(15), 1788. (10.1029/ 2003GL017675.)
Hofmann, D.J., J.M. Rosen, J.W. Harder and S.R. Rolf. 1987. Observations of the decay of the El Chichón stratospheric aerosol cloud in Antarctica. Geophys. Res. Lett., 14(6), 614-617.

Hvidberg, C.S., J.P. Steffensen, H.B. Clausen, H. Shoji and J. Kipfstuhl. 2002. The NorthGRIP ice-core logging procedure: description and evaluation. Ann. Glaciol., 35, 5-8.

Johnsen, S.J. and 8 others. 2001. Oxygen isotope and palaeotemperature records from six Greenland ice-core stations: Camp Century, Dye-3, GRIP, GISP2, Renland and NorthGRIP. J. Quat. Sci., 16(4), 299-307.

Jouzel, J. and 12 others. 2001. A new 27 kyr high resolution East Antarctic climate record. Geophys. Res. Lett., 28(16), 31993202.

Langway, C.C., Jr, K. Osada, H.B. Clausen, C.U. Hammer and H. Shoji. 1995. A 10-century comparison of prominent bipolar volcanic events in ice cores. J. Geophys. Res., 100(D8), 16,24116,247 .

Legrand, M. and R.J. Delmas. 1987. A 220-year continuous record of volcanic $\mathrm{H}_{2} \mathrm{SO}_{4}$ in the Antarctic ice sheet. Nature, 327(6124), $671-676$

Legrand, M. and D. Wagenbach. 1999. Impact of the Cerro Hudson and Pinatubo volcanic eruptions on the Antarctic air and snow chemistry. J. Geophys. Res., 104(D1), 1581-1596.

Moore, J.C., R. Mulvaney and J.G. Paren. 1989. Dielectric stratigraphy of ice: a new technique for determining total ionic concentrations in polar ice cores. Geophys. Res. Lett., 16(10), 1177-1180.

Palais, J.M., I.M. Whillans and C. Bull. 1982. Snow stratigraphic studies at Dome C, East Antarctica: an investigation of depositional and diagenetic processes. Ann. Glaciol., 3, 239-242.

Petit, J.R., J. Jouzel, M. Pourchet and L. Merlivat. 1982. A detailed study of snow accumulation and stable isotope content in Dome C (Antarctica). J. Geophys. Res., 87(C6), 4301-4308.

Petit, J.R. and 18 others. 1999. Climate and atmospheric history of the past 420,000 years from the Vostok ice core, Antarctica. Nature, 399(6735), 429-436.

Robock, A. and M.P. Free. 1995. Ice cores as an index of global volcanism from 1850 to the present. J. Geophys. Res., 100(D6), 11,549-11,567.

Rosen, J.M., N.T. Kjome, R.L. McKenzie and J.B. Liley. 1994. Decay of Mount Pinatubo aerosol at midlatitudes in the northern and southern hemispheres. J. Geophys. Res., 99(D12), 25,73325,739 .

Schwander, J., A. Neftel, H. Oeschger and B. Stauffer. 1983. Measurement of direct current conductivity on ice samples for climatological applications. J. Phys. Chem., 87(21), 4157-4160.

Schwander, J., J. Jouzel, C.U. Hammer, J.R. Petit, R. Udisti and E. Wolff. 2001. A tentative chronology for the EPICA Dome Concordia ice core. Geophys. Res. Lett., 28(22), 4243-4246.

Stauffer, B., J. Flückiger, E.W. Wolff and P.R.F. Barnes. 2004. The EPICA deep ice cores: first results and perspectives. Ann. Glaciol., 39, 93-100.

Udisti, R. and 8 others. 2004. Stratigraphic correlation between the EPICA-Dome $\mathrm{C}$ and Vostok ice cores showing the relative variations of snow accumulations over the past 45 kyr. J. Geophys. Res., 109(D8), D08101. (10.1029/ 2003JD004180.)

Wolff, E. 2000. Electrical stratigraphy of polar ice cores: principles, methods, and findings. In Hondoh, T., ed. Physics of ice core records. Sapporo, Hokkaido University Press, 155-171.

Wolff, E., I. Basile, J.R. Petit and J. Schwander. 1999. Comparison of Holocene electrical records from Dome C and Vostok, Antarctica. Ann. Glaciol., 29, 89-93. 